\title{
Research on Agent-based Command Decision Simulation
}

\author{
Peng Cui ${ }^{*}$, Wei Chu and Yuping Li \\ Science and Technology on Information Systems Engineering Laboratory, Nanjing, China \\ ${ }^{*}$ Corresponding author
}

\begin{abstract}
Command decision simulation is one of the key parts of C4ISR system simulation, and it is also one of the key technologies of Tactical Simulation Experiment platform. Taking the tactical command decision-making process as an example, the framework of command decision model based on Agent is established. And the model of command decision process is designed and implemented.
\end{abstract}

Keywords-simulation; agent; combat decision

\section{INTRODUCTION}

Command decision simulation is the simulation of the capability, knowledge, behavior and process of tactical commanders facing various battlefield situations. The commanders make attack or defense action decision according to the combat task, target information and the combat status of the subordinate forces. And the military situation, weapons performance, combat tasks, war tactical thinking and combat principle are considered as the basis for decision making [1]. Command decision simulation is an intelligent decision-making system based on knowledge architecture, which reflects the commander's tactical thinking, decision-making ability, personality characteristics and command methods. It is necessary to meet the needs of combat research to improve the scientific of combat decision, but also should be an open, can be characterized, evolving system. With depth research, the simulation of different combat objects, different training level and commanders of different personalities become more and more complex. In order to better meet the Military Tactical Simulation Experimental Research on demand, a scientific technique and approach is needed to reduce the coupling degree of simulation models, and to improve the flexibility and reusability of the system.

Agent has the autonomy, sociality, reactivity, initiative, adaptability and collaboration features, which is similar to the decision-making process; therefor the Agent-based method is suitable for of command decision simulation modeling. Because of too many factors of strategic and operational level command decision involved, including the commander's knowledge, experience and personalities, and the battlefield situation, it is seriously hard to realistic simulate the command decision process and behavior of the strategic and operational level. At present, the Agent-based strategic level command decision model is still in the stage of exploration, which is far from the actual application requirements, but the tactical level model has been applied in practice [2][3][4].Taking the tactical command decision-making process as an example, we establish the framework of command decision model based on Agent, model the command decision process, design and implement the simulation model. The Decision Rule Base and Decision Processing Agent need to be set up according to the specific command \& control (C2) system, so it is difficult to establish a general simulation model for all commanders and C2 systems.

\section{FrameWORK OF SimUlation Model}

The Agent-based framework of command decision simulation model uses Agent technology to simulate the complex command decision-making process and behavior of man-machine combination at the tactical level, and its function mainly includes three aspects:

- Provides man-machine interaction simulation representations of tactical command decision behavior;

- Command decision model provides general Agentbased framework of command decision for each C2 action, which simulating the commanders' decisionmaking process, and generating combat action plans, and commands, etc.;

- Distribute the combat action plans and commands to the superior/subordinate/friendly command decision system models and force models.

\section{A. General Framework}

Through the analysis of the function and characteristics of the command decision simulation model, a general framework of command decision simulation model based on Agent is established. The framework is composed of script editing module, script parsing and processing module, multi-Agent module, communication service, man-machine interface and decision rule base, as shown in Figure 1.

- Script editing module: provides script editing capabilities for users and generates script files. The module only edits the scripts of Agent internal processing rules and generates the internal rule files.

- Script parsing and processing module: parses and processes the script files which generated by users. And each Agent is able to use the internal rules files generated after parsing which should be put into the specified location of the system.

- Multi-Agent module: models the command decision process with multiple Agent modules, which composed 
of commander Agent and decision-making Agents. The commander Agent completes the rule reasoning of the key process of command decision-making, as well as the scheduling control of multiple decision-making Agents. The decision-making Agent performs the reasoning of multiple decision sub processes in the command decision process, such as threat assessment, troop allocation and planning, etc. The decisionmaking Agent is not necessary, and the required count of Agents is determined by the complexity and characteristics of different fields of command decision process. Each Agent has its own decision rule base, not only can make command decisions independently, and also can cooperate with each other according to their own conditions and battlefield environment to complete the command decision-making simulation.

- Communication service: provides communication capabilities among individual Agents.

- Man-machine interface: shows real-time situation and C2 process, and also provides the commander intervention interface.

- Decision rule base: stores the internal processing rules of Agents. It can be expanded and updated, so that the rules required for command decision simulation are constantly enriched and improved.

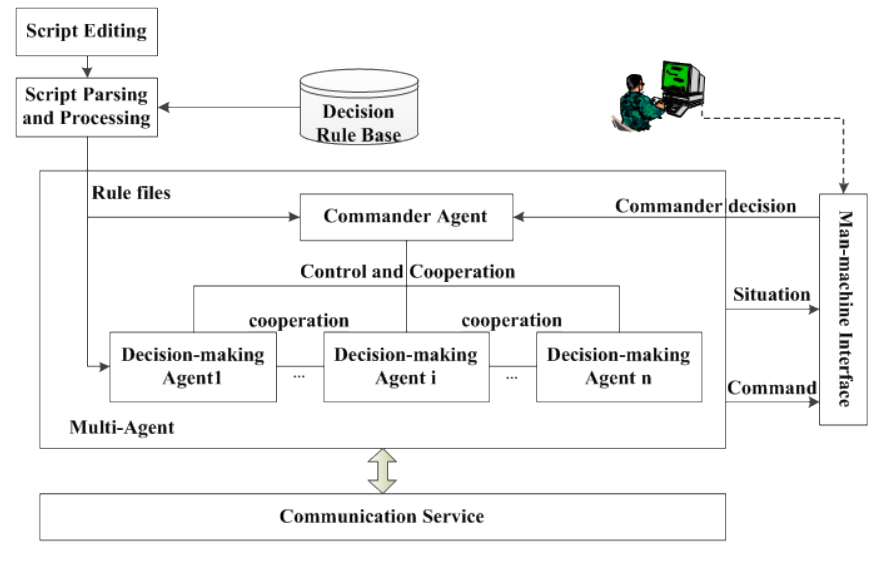

FIGURE I. AGENT-BASED SIMULATION MODEL

\section{B. Commander Agent Simulation Model}

Commander Agent forms the combat plan and commands through analyzing the battlefield comprehensive situation. According to the procedure of command decision-making, the related military rules and the principle of dealing with special events, we build the General Commander Agent framework as shown in Figure 2.

The framework has certain versatility in the field of command decision simulation, and is suitable for all kinds of C2 system simulation modeling. The Agent model includes multiple modules such as communication, core processing, man-machine interface, learning module, interpreter, and decision response libraries. And the core processing module is divided into two main parts of the main monitoring module and the decision module.

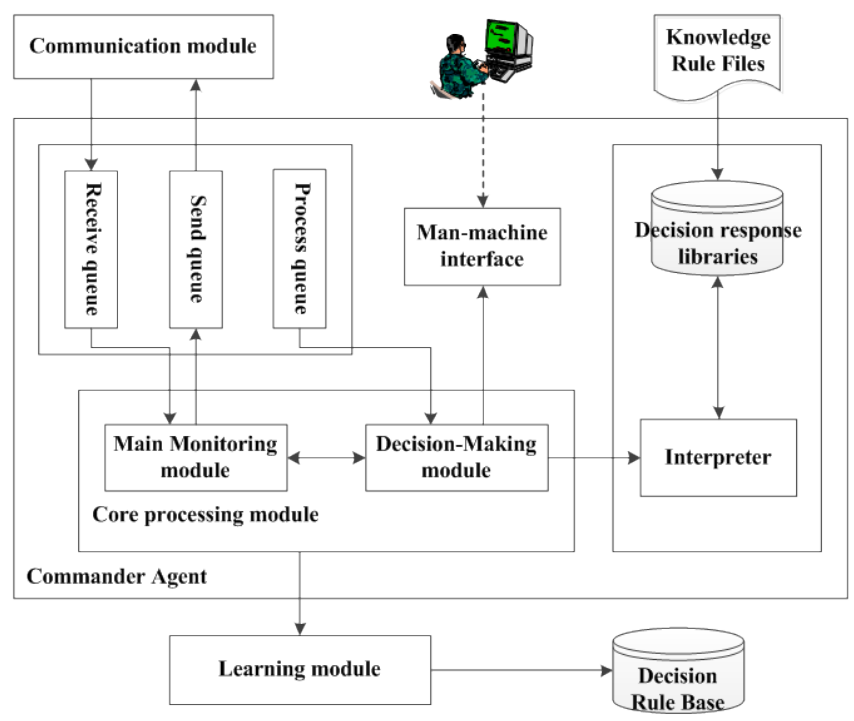

FIGURE II. COMMANDER AGENT SIMULATION MODEL

- Communication module: completes the communication between Agent and the external environment to receive, store and transmit information. It also has functions of managing the information queues.

- Man-machine interface: provides the communication interface between the commander and the core processing module.

- Core processing module: processes command decisionmaking and manage the Agents. The main monitoring module mainly deals with the management information such as the state of the Agent and the cooperative messages. And the decision module makes decision reasoning and obtains the decision results under the coordination of the interpreter by certain military rules, according to the task requirements of the Agent. This process is the direct representation of Agent intelligence behavior.

- Decision response libraries: stores and manage the knowledge rule files used by the Agent, and provides the knowledge rule files information to interpreter during the course of work.

- Interpreter: completes rule interpretation and reasoning. After the start of the work, data exchange has been carried out with the core processing module. Interpreter loads the corresponding rule information from the decision response libraries, explain the data and return the result to the core processing module.

- Learning module: completes the process of rule selflearning. Through the analysis of characteristic data and decision results, regular learning is carried out.

\section{COMMAND DECISION SIMULATION MODELING}

\section{A. Logic Flow of Command Decision}

The logical flow of command decisions is shown in Figure 3. Calculates the motion parameters when a target is founded 
obtain target comprehensive information by threat assessment and attack analysis for the target. Then make attack/defensive decisions and implement command according to the current operational situation. Command decision-making is the core of air defense combat capability. When a decision is made for an attack, determine the weapon's use plan, including the type, quantity, and mode of attack. Otherwise determine defensive goals and ways of defense. At the same time of operation, it is possible to change the attack and defense status with the change of battlefield situation.

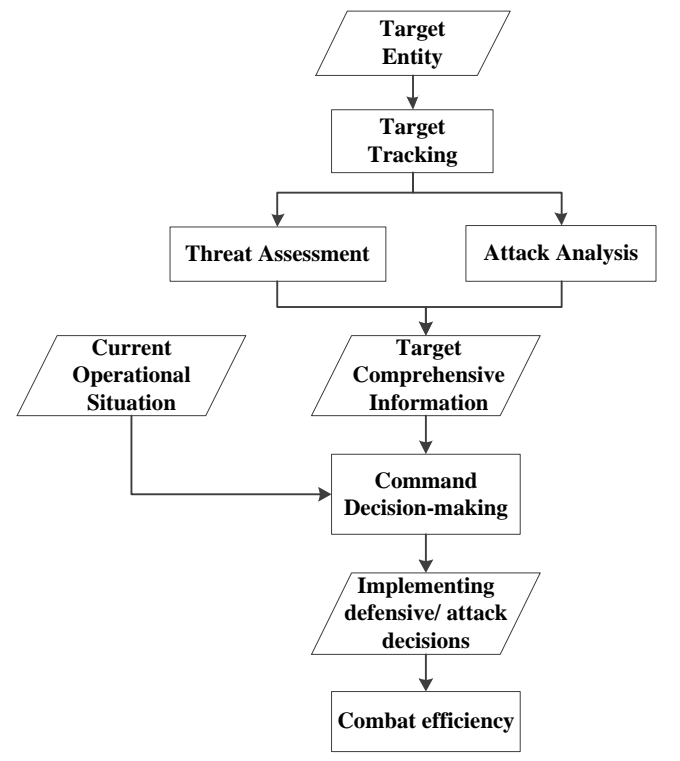

FIGURE III.

LOGIC FLOW OF COMMAND DECISION

The input data of command decision-making include target comprehensive information and current combat status information of subordinate weapons. Among them, the target comprehensive information includes target count, type, movement factor, threat intensity and offensive data. Subordinate weapon combat status information describes the state of weapon attack and defense systems. The output data of command decision-making is attack/defense command to subordinate weapons. The attack commands include missile attack, air attack, torpedo attack and so on. The defense commands include missile defensive, air intercept, torpedo interception and so on. The implementation process of the simulation of every command decision, constantly changing battlefield situation, target information and weapon state may change, these changes of information continues as input data to command decision-making for the next step, so as to realize the simulation of tactical command process.

\section{B. Command Decision-making Model}

The command decision-making model is actually a decision knowledge base composed of multiple production rules. The production rule describes the decision knowledge that is converted to a new state when the decision condition is satisfied in the current state. The basic structure of the command decision-making model is described in Table 1. In detail, a subset of command decision rules under the condition of "tracking target" is given. The rules for conflict resolution strategy are not discussed in this article which needed when a number of rules are met at the same time.

TABLE I. BASIC STRUCTURE OF COMMAND DECISION MODEL

\begin{tabular}{|c|c|c|}
\hline Current State & $\begin{array}{c}\text { Decision-Making } \\
\text { Conditions }\end{array}$ & New State \\
\hline \multirow{3}{*}{ Target Detection } & New Target & Target Tracking \\
\hline & New Target \& Missile & Missile Warning \\
\hline & New Target \& Torpedo & Torpedo Warning \\
\hline Missile Warning & High Threat Level & $\begin{array}{l}\text { Missile } \\
\text { Interception }\end{array}$ \\
\hline Torpedo Warning & High Threat Level & $\begin{array}{l}\text { Torpedo } \\
\text { Interception }\end{array}$ \\
\hline \multirow{4}{*}{ Target Tracking } & $\begin{array}{l}\text { Aircraft \& High Threat } \\
\text { Level \& Missile Attack } \\
\text { Invalid }\end{array}$ & Air Intercept \\
\hline & $\begin{array}{l}\text { Ship \& High Threat } \\
\text { Level \& Torpedo Attack } \\
\text { Invalid }\end{array}$ & Ship Defense \\
\hline & $\begin{array}{l}\text { Aircraft/Ship \& High } \\
\text { Threat Level \& Missile } \\
\text { Attack Valid }\end{array}$ & Missile Attack \\
\hline & $\begin{array}{l}\text { Aircraft/Ship \& High } \\
\text { Threat Level \& Torpedo } \\
\text { Attack Valid }\end{array}$ & Torpedo Attack \\
\hline Missile Interception & $\ldots$ & $\ldots$ \\
\hline Torpedo Interception & $\ldots$. & $\ldots$ \\
\hline Air Intercept & $\ldots$ & $\ldots$ \\
\hline Ship Defense & $\cdots$ & $\cdots$ \\
\hline Missile Attack & $\ldots$ & $\ldots$ \\
\hline Torpedo Attack & $\ldots$ & $\ldots$ \\
\hline
\end{tabular}

IV. DECISION RULE DESIGN

\section{A. Decision Rule Base}

Decision rule base is the basis for each Agent in the command decision system to respond to the battlefield situation and carry out cognitive reasoning. It is the basement rule support of Agent command decision-making.

\section{TABLE II. RULE LIBRARY TYPES AND THEIR DESCRIPTIONS}

\begin{tabular}{|c|c|c|}
\hline \multicolumn{2}{|c|}{ Rule Type } & Description \\
\hline \multirow{3}{*}{$\begin{array}{c}\text { Threat } \\
\text { Level } \\
\text { Judgment } \\
\text { Rules }\end{array}$} & $\begin{array}{c}\text { Target } \\
\text { Type } \\
\text { Judgment }\end{array}$ & $\begin{array}{l}\text { The types of incoming aircraft, different } \\
\text { types of aircraft, have different levels of } \\
\text { threat }\end{array}$ \\
\hline & $\begin{array}{l}\text { Relative } \\
\text { Distance } \\
\text { Judgment }\end{array}$ & $\begin{array}{l}\text { The relative distance between the } \\
\text { incoming aircraft and the command post } \\
\text { can be calculated according to the } \\
\text { location of the incoming target in the } \\
\text { intelligence and the location of the } \\
\text { command post. The relative distances } \\
\text { are different, and the threat levels are } \\
\text { different }\end{array}$ \\
\hline & $\begin{array}{l}\text { Relative } \\
\text { Orientation } \\
\text { Judgment }\end{array}$ & $\begin{array}{l}\text { The relative positions of incoming } \\
\text { aircraft and the command post can } \\
\text { obtain relative azimuth, relative azimuth } \\
\text { angle, and threat level according to the } \\
\text { direction of the incoming target and the } \\
\text { direction of the command post in the } \\
\text { intelligence }\end{array}$ \\
\hline
\end{tabular}




\begin{tabular}{|c|c|c|}
\hline \multicolumn{2}{|c|}{ Rule Type } & Description \\
\hline & $\begin{array}{l}\text { Arrival } \\
\text { Time } \\
\text { Estimation }\end{array}$ & $\begin{array}{l}\text { Incoming aircraft arriving at the } \\
\text { command of the time, according to the } \\
\text { information of the current position and } \\
\text { the target position command, and the } \\
\text { target speed can be calculated and } \\
\text { estimated time of arrival, arrive at the } \\
\text { same time, the threat level is different }\end{array}$ \\
\hline & $\begin{array}{c}\text { Threat } \\
\text { Estimation } \\
\text { Coefficient }\end{array}$ & $\begin{array}{l}\text { Considering the influence of various } \\
\text { factors on target threat level, the } \\
\text { weighting coefficient of threat grade } \\
\text { calculated by various factors is } \\
\text { determined }\end{array}$ \\
\hline \multicolumn{2}{|c|}{ Target Intercept Rules } & $\begin{array}{l}\text { When the blue target threat level reaches } \\
\text { a certain level, it is necessary to assign } \\
\text { troops to intercept the target. When } \\
\text { receiving the command intercepted by } \\
\text { the higher command, it is necessary to } \\
\text { assign troops to intercept the target }\end{array}$ \\
\hline \multirow{2}{*}{$\begin{array}{l}\text { weapons } \\
\text { Assignment } \\
\text { Rules }\end{array}$} & $\begin{array}{l}\text { Weapon } \\
\text { Type } \\
\text { Selection }\end{array}$ & $\begin{array}{l}\text { Depending on the height of incoming } \\
\text { targets provided in the intelligence } \\
\text { information, different intercepting } \\
\text { weapons, such as anti-aircraft guns and } \\
\text { surface to air missiles, are chosen }\end{array}$ \\
\hline & $\begin{array}{l}\text { Aviation } \\
\text { Choice }\end{array}$ & $\begin{array}{l}\text { In the case of incoming aircraft } \\
\text { interception, according to the state of our } \\
\text { aircraft, the development of appropriate } \\
\text { interception rules }\end{array}$ \\
\hline
\end{tabular}

Decision rule base mainly includes the rules such as threat rank judgment, target interception, weapon assignment and so on. It should be pointed out that it is very complicated to construct a set of complete behavior state sets for tactical command and decision systems, this paper only gives a set of rules for the tactical defensive behavior set of tactical air defense. The key point is to give the design and implementation of the decision rule base, and the design goal is to make the rule base can be a good extended. The rule type and description of the rule base are shown in Table 2.

\section{B. Decision Rule Representation}

The command decision rules in this article are stored in XML format. The user edits a rule script that parses and makes error checks by lexical analysis, syntax analysis and part semantic analysis of the script files. If passed the check, the grammar structure of the language description in the script file is first generated, and then translates the script file into XML files that are stored in fixed grammatical form based on the syntax tree.

In the process of syntax tree storage, first take a note of the first layer of the syntax tree, determine whether the syntax tree is sentence format or compound format. If it is a compound statement, take the first sub sentence, and use the above process to judge it recursively. If it is sentence format, store the sentence directly. According to different sentence types, store the sentence in different structures and formats. For example, the IF statement stores the statement type IF first, then sequentially stores the syntax semantic information of the IF condition, the Then statement, and the Else statement. Other types of sentences are stored separately according to the sentence structure; storage is similar to the process.
After the parse and storage of the syntax tree, the XML format file for storing the information is generated directly, and the Schema description is shown in Figure 4.

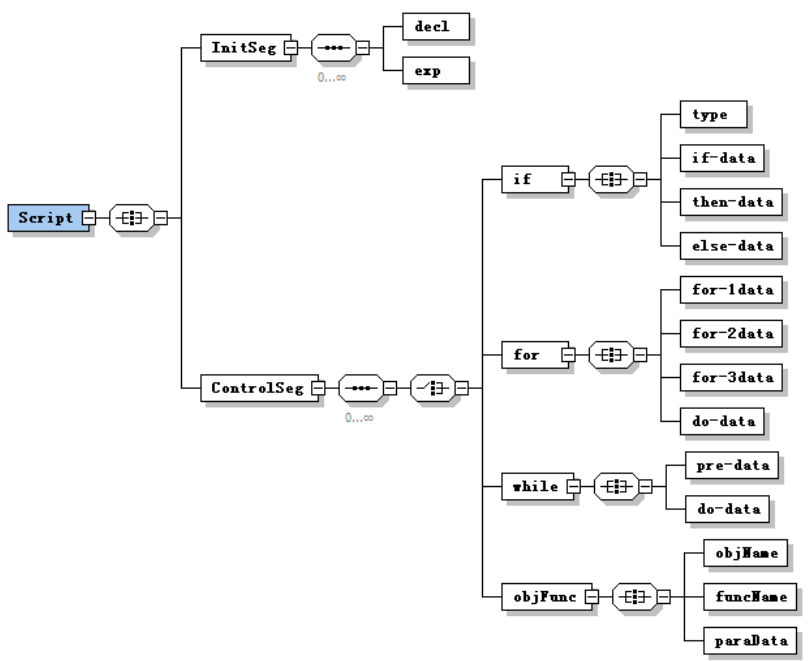

FIGURE IV.

THE XML FORMAT OF THE RULE FILE

Corresponding to the user's rule script syntax, the storage of the rule file is divided into two parts: the initial segment section (InitSeg) and the control section (ControlSeg). The InitSeg records declaration (decl) and experiment (exp) information. The ControlSeg records conditional judgment (if) and response behavior (for, while, objFunc) information. This description is designed to enable the interpreter to recognize these stored data information in the interpretation of the reasoning process so that users can flexibly edit rules using scripts. And the Agent performs its reasoning on the basis of the explanatory intermediate file.

\section{ACKNOWLEDGMENT}

In this paper, the function of C4ISR command decisionmaking system is analyzed, and the simulation modeling method based on Agent is applied to tactical command \& control system. Using the framework of command decisionmaking simulation model based on Agent described above, an Agent-based simulation model of command decision system is established, and the kernel part (representation of decision rules) is designed.

\section{REFERENCE}

[1] Chen Jianhua, et al. Research of Warship CGF Battle Decision-Making Simulation Based on Rule Engine [C]. fourteenth Conference on system simulation: Sanya, system simulation society, 2012.

[2] Mao Shaojie, et al. C4ISR system simulation test technology Beijing: Military Science Press, 2012.

[3] DU Wei ZHU Jiang WEN Chuanhua WANG Yingchun. Operational System Emulation Modeling Based on Multi-Agent[J]. Ship Electronic Engineering,2016.

[4] Mi Yulin, Guo Zhijie, Jiang Wenzhi, Liu Tao. Command and Decision Architecture of Key Positions Air-defense Based on Multi-Agent [J]. Command, control and simulation, 2016. 